\title{
Delineating the Risk of Lupus Nephritis: How Far Have We Come?
}

Jisoo Lee, M.D., Ph.D.

Division of Rheumatology, Department of Internal Medicine, Ewha Womans University College of Medicine, Seoul, Korea

Lupus nephritis (LN) is a common and severe manifestation of systemic lupus erythematosus (SLE), which puts a substantial burden on patients living with the disease. Over half of the patients with SLE will develop LN during the course of the disease [1], with approximately $10 \%$ progressing to end-stage renal disease and $10 \% \sim 20 \%$ dying within 10 years [2-4]. The pathogenesis of SLE is complex. Multiple factors including genetic, hormonal, immunologic, and environmental factors, are linked to SLE pathogenesis, resulting in diverse clinical manifestations and varieties of associated autoantibodies $[5,6]$. The presence of specific disease manifestation, such as LN, is also influenced by the risk factors associated with generalized SLE [7]. In LN, these risk factors contribute to not only the development of manifestation, but also the outcome and overall prognosis. However, there are still controversies regarding the strength of the association for many of these factors with the presence and prognosis of $\mathrm{LN}$, since most of the data originates from observation studies looking into a narrow spectrum of risk factors. A recent article by Shin et al. [8] published in the Journal of Rheumatic Diseases provides data regarding clinical and genetic risk factors associated with the presence of LN in ethnically homogeneous Korean patients.

In this prospective observational study, the authors compared 507 SLE patients having biopsy proven LN with those without LN to identify genetic, immunologic, and clinical factors related to the presence of LN. The analysis revealed that clinical features, such as younger age at diagnosis, and the presence of pleuritis and peri- carditis, were associated with the presence of $\mathrm{LN}$. The presence of anti-double stranded deoxyribonucleic acid (anti-dsDNA) antibodies, anti-Smith (anti-Sm) antibodies, low levels of complement, and absence of antiphospholipid (aPL) antibodies were identified as immunologic factors associated with the presence of LN. In addition, a higher weighted genetic risk score (wGRS) predicted the evelopment of LN by having effects on anti-Sm antibody positivity and decrease in complement levels. The authors concluded that onset age, pleuritis, pericarditis, serological markers, and a high wGRS were associated with the presence of $\mathrm{LN}$.

Previous studies have demonstrated that demographic factors, such as ethnicity, age, and sex, play an important role in the development of LN. Non-European populations, younger age, and male sex have been reported to be associated with the occurrence of LN [9-12]. In addition, clinical and serological factors, such as thrombocytopenia, leukopenia, hemolytic anemia, malar rash, low complement levels, and presence of autoantibodies, such as anti-DNA, anti-Sm, anti-SSA/SSB, anti-RNP, and lupus anticoagulant, have been reported as significant predictors of the occurrence of $\mathrm{LN}[2,12-16]$. In accordance with previous studies, the study by Shin et al. [8] also identified younger age at diagnosis, low levels of complement, and presence of anti-dsDNA and anti-Sm as significant factors associated with the presence of LN. However, this study identified pleuritis, pericarditis, and absence of aPL as distinctive factors associated with the presence of LN in the Korean population [8].

It is unclear whether the association between these re-

Received : August 13, 2021, Accepted : August 27, 2021

Corresponding to : Jisoo Lee (iD http://orcid.org/0000-0001-6279-7025

Division of Rheumatology, Department of Internal Medicine, Ewha Womans University College of Medicine, 1071 Anyangcheon-ro, Yangcheon-gu, Seoul 07985, Korea. E-mail : leejisoo@ewha.ac.kr

Copyright (C) 2021 by The Korean College of Rheumatology.

This is an Open Access article, which permits unrestricted non-commerical use, distribution, and reproduction in any medium, provided the original work is properly cited. 
ported risk factors and LN is mainly due to genetic influence or the contribution of socio-environmental factors. Although socio-economic factors, such as poor access to treatment due to cost and nonadherence, have been shown to be linked to severe $\mathrm{LN}$ and worse prognosis, genetic etiology is speculated to play a significant role in the development of renal manifestations in SLE $[17,18]$. It has been suggested that older and younger onset patients respond to different triggering mechanisms for the development of LN because of differences in genetic predisposition $[19,20]$. A number of genetic polymorphisms have been reported to be associated with LN. The cell surface receptors Fc $\gamma$ RIIa (CD32) and Fc $\gamma$ RIIIa (CD16), which are responsible for binding to the immunoglobulin subclass and the clearance of immune complexes, were shown to be heritable risk factors for $\mathrm{LN}[21,22]$. In a genome-wide association study of LN, both major histocompatibility complex (MHC) genes linked to the immune response to self-antigen (HLA-DR2 and HLA-DR3) and non-MHC genes linked to regulatory role in inflammation (platelet-derived growth factor receptor $\alpha$, PDGFRA) were shown to have strong associations with LN [23]. In a multi-ethnic cohort study using a genome-wide gene-based approach, tripartite motif (TRIM) proteins, which have important roles in innate immunity and antiviral defense, were associated with LN in South Europeans, whereas the TTC34 gene conferring vulnerability to somatic mutations was associated with $\mathrm{LN}$ among Hispanics [24]. In the same study, single-nucleotide polymorphisms in the chronic kidney disease risk alleles of NFATC1, which is involved in the activation of the T-cell antigen receptor were shown to be associated with LN across ethnicity [24].

The GRS is commonly used to evaluate the cumulative effects of many genetic factors on clinical outcomes. The GRS can estimate a risk a person has for developing an outcome based on their genotypes at variants determined to be associated with the risk factor [25]. The GRS has been applied in various fields of medicine to predict the risk of diseases such as cardiovascular disease and prostate cancer [26,27]. Recently, to test the usefulness of genetic profiling in predicting outcomes in patients with SLE, the GRS was applied for assessing the risk of SLE disease outcomes. In this study, a high GRS was associated with increased risks of organ damage, renal dysfunction and all-cause mortality [28]. A study by Shin et al. applied the GRS to identify the genetic risk associated with the presence of $\mathrm{LN}$. They reported that a high wGRS increased the likelihood of developing LN, and this association between a high wGRS and LN was mediated by anti-Sm and low complement levels [8].

The study by Shin et al. [8] is important in many ways. First, it fills in the knowledge gap regarding the risk factors associated with $\mathrm{LN}$ in the ethnically homogenous Korean population. Second, it is powered by evaluating the cumulative effects of many genetic factors on the occurrence of LN. Third, the study utilized a statistical method, that is, mediation analysis, to understand the mediational process between genetic risk factors and the development of LN [29].

The article contributes to current knowledge that the development of $\mathrm{LN}$ is associated with a vast array of genetic, demographic, clinical, and serological factors. In addition, this article suggests future promise for applying the GRS to predict the development of LN. To implement these risk factors, including the GRS to predict the risk of LN development, we need more studies looking into the relevance and reliability of each risk factor. However, considering that a wealth of new technologies is becoming increasingly available, we will soon be able to predict the development of the important manifestations of a complex disease, such as LN, in the clinic.

\section{CONFLICT OF INTEREST}

No potential conflict of interest relevant to this article was reported.

\section{REFERENCES}

1. Tsokos GC. Systemic lupus erythematosus. N Engl J Med 2011;365:2110-21.

2. Hanly JG, O'Keeffe AG, Su L, Urowitz MB, Romero-Diaz J, Gordon C, et al. The frequency and outcome of lupus nephritis: results from an international inception cohort study. Rheumatology (Oxford) 2016;55:252-62.

3. Zhang L, Lee G, Liu X, Pascoe EM, Badve SV, Boudville NC, et al. Long-term outcomes of end-stage kidney disease for patients with lupus nephritis. Kidney Int 2016;89:1337-45.

4. Vandepapelière J, Aydin S, Cosyns JP, Depresseux G, Jadoul M, Houssiau FA. Prognosis of proliferative lupus nephritis subsets in the Louvain Lupus Nephritis inception Cohort. Lupus 2014;23:159-65.

5. Lisnevskaia L, Murphy G, Isenberg D. Systemic lupus erythematosus. Lancet 2014;384:1878-88.

6. Wahren-Herlenius M, Dörner T. Immunopathogenic mechanisms of systemic autoimmune disease. Lancet 2013;382: 819-31.

7. Ntatsaki E, Isenberg D. Risk factors for renal disease in systemic lupus erythematosus and their clinical implications. 
Expert Rev Clin Immunol 2015;11:837-48.

8. Shin JM, Kim D, Kwon YC, Ahn GY, Lee J, Park Y, et al. Clinical and genetic risk factors associated with the presence of lupus nephritis. J Rheum Dis 2021;28:150-8.

9. Ho CT, Mok CC, Lau CS, Wong RW. Late onset systemic lupus erythematosus in southern Chinese. Ann Rheum Dis 1998;57:437-40.

10. Formiga F, Moga I, Pac M, Mitjavila F, Rivera A, Pujol R. Mild presentation of systemic lupus erythematosus in elderly patients assessed by SLEDAI. SLE Disease Activity Index. Lupus 1999;8:462-5.

11. Seligman VA, Lum RF, Olson JL, Li H, Criswell LA. Demographic differences in the development of lupus nephritis: a retrospective analysis. Am J Med 2002;112:726-9.

12. Alba P, Bento L, Cuadrado MJ, Karim Y, Tungekar MF, Abbs I, et al. Anti-dsDNA, anti-Sm antibodies, and the lupus anticoagulant: significant factors associated with lupus nephritis. Ann Rheum Dis 2003;62:556-60.

13. Reppe Moe SE, Molberg $\varnothing$, Strøm EH, Lerang K. Assessing the relative impact of lupus nephritis on mortality in a population-based systemic lupus erythematosus cohort. Lupus 2019;28:818-25.

14. Tanha N, Hansen RB, Nielsen CT, Faurschou M, Jacobsen S. Clinical and serological associations with the development of incident proteinuria in Danish patients with systemic lupus erythematosus. J Rheumatol 2018;45:934-41.

15. Bastian HM, Roseman JM, McGwin G Jr, Alarcón GS, Friedman AW, Fessler BJ, et al. Systemic lupus erythematosus in three ethnic groups. XII. Risk factors for lupus nephritis after diagnosis. Lupus 2002;11:152-60.

16. Duarte-García A, Barr E, Magder LS, Petri M. Predictors of incident proteinuria among patients with SLE. Lupus Sci Med 2017;4:e000200.

17. Barr RG, Seliger S, Appel GB, Zuniga R, D'Agati V, Salmon $\mathrm{J}$, et al. Prognosis in proliferative lupus nephritis: the role of socio-economic status and race/ethnicity. Nephrol Dial Transplant 2003;18:2039-46.

18. Petri M, Perez-Gutthann S, Longenecker JC, Hochberg M. Morbidity of systemic lupus erythematosus: role of race and socioeconomic status. Am J Med 1991;91:345-53.
19. Bell DA. SLE in the elderly--is it really SLE or systemic Sjögren's syndrome? J Rheumatol 1988;15:723-4.

20. Catoggio LJ, Skinner RP, Smith G, Maddison PJ. Systemic lupus erythematosus in the elderly: clinical and serological characteristics. J Rheumatol 1984;11:175-81.

21. Salmon JE, Millard S, Schachter LA, Arnett FC, Ginzler EM, Gourley MF, et al. Fc gamma RIIA alleles are heritable risk factors for lupus nephritis in African Americans. J Clin Invest 1996;97:1348-54.

22. Karassa FB, Trikalinos TA, Ioannidis JP; FcgammaRIIa-SLE Meta-Analysis Investigators. Role of the Fcgamma receptor IIa polymorphism in susceptibility to systemic lupus erythematosus and lupus nephritis: a meta-analysis. Arthritis Rheum 2002;46:1563-71.

23. Chung SA, Brown EE, Williams AH, Ramos PS, Berthier $\mathrm{CC}$, Bhangale $\mathrm{T}$, et al. Lupus nephritis susceptibility loci in women with systemic lupus erythematosus. J Am Soc Nephrol 2014;25:2859-70.

24. Lanata CM, Nititham J, Taylor KE, Chung SA, Torgerson DG, Seldin MF, et al. Genetic contributions to lupus nephritis in a multi-ethnic cohort of systemic lupus erythematous patients. PLoS One 2018;13:e0199003.

25. Igo RP Jr, Kinzy TG, Cooke Bailey JN. Genetic risk scores. Curr Protoc Hum Genet 2019;104:e95.

26. Krarup NT, Borglykke A, Allin KH, Sandholt CH, Justesen $\mathrm{JM}$, Andersson EA, et al. A genetic risk score of 45 coronary artery disease risk variants associates with increased risk of myocardial infarction in 6041 Danish individuals. Atherosclerosis 2015;240:305-10.

27. Helfand BT. A comparison of genetic risk score with family history for estimating prostate cancer risk. Asian J Androl 2016;18:515-9.

28. Reid S, Alexsson A, Frodlund M, Morris D, Sandling JK, Bolin $\mathrm{K}$, et al. High genetic risk score is associated with early disease onset, damage accrual and decreased survival in systemic lupus erythematosus. Ann Rheum Dis 2020;79: 363-9.

29. MacKinnon DP, Fairchild AJ, Fritz MS. Mediation analysis. Annu Rev Psychol 2007;58:593-614. 